\title{
Study on Establishment of Enterprise Financial Risk Assessment Model Based on Entropy Weight TOPSIS
}

\author{
Taiyu Wang ${ }^{1, *}$, Xianhui Deng ${ }^{2}$ \\ ${ }^{1}$ School of Advanced Studies, Saint Louis University, Baguio City, Benguet, Philippines, 2600 \\ ${ }^{2}$ School of Economics and Management, Tibet University, Lhasa City, Tibet Autonomous Region, China, 850000 \\ Corresponding author's email: wangtaiyu0906@16.com
}

\begin{abstract}
More and more enterprises have realized the importance of financial risk management. Financial risk can lead to operational losses and reputational damage, but it can also bring potential benefits. If companies focus on expected risks, combining risk management with corporate strategies can better achieve strategic goals and improve competitiveness. This paper uses Entropy Weight TOPSIS to analyze the main financial indicators and establish a financial risk assessment model to help companies apply the dynamic financial risk management process in their business management.
\end{abstract}

Keywords: Enterprise financial risk; entropy weight TOPSIS; financial risk assessment model

\section{INTRODUCTION}

Risk is the uncertainty that something will happen. Suppose a company manages to reduce the losses caused by risk or turn risk into opportunities. In that case, it can be said that it has an effective risk management mechanism.

Financial risk is an objective risk in a company's operation, which occurs due to the uncertainty of repaying the company's debts. The causes of financial risk are also diverse and include improper financing methods, unreasonable financial structure, poor asset management, and irrational investment decisions [1]. However, financial risk is not necessarily a hindrance to business growth. For example, if a firm takes a loan from a bank to invest in a new business, the loan will increase the firm's liquidity risk, but the result may be potentially rewarding. Therefore, the identification and measurement of risk need to be integrated with the of the firm's financial situation.

There are various reasons for the generation of enterprise financial risks, and the causes of different financial risks are different. Generally speaking, the financial risks faced by enterprises are mainly caused by internal management factors and external macro factors. The external environment mainly includes the macroeconomic environment, social environment, market environment and legal environment ${ }^{[1]}$. The constant changes in the external environment are difficult to predict and control, affecting internal decision decision-making and leading to financial risks. In addition, changes in supply and demand in the market can also affect enterprises' production and operation activities. Supply and demand information is not fully transparent in the market, so there is greater uncertainty in the enterprise's decision-making, which risks enterprise's operation.

The external risks faced by enterprises in the same region are roughly the same. Therefore, the factors affecting the financial risk of enterprises are mainly the internal management of enterprises, and the internal factors of enterprises are mainly the following aspects ${ }^{2-}$ 4].

1) Lack of objective understanding of risk by enterprise financial personnel. In business activities, financial managers do not realize that risks exist in every process of financial activities, and do not take the initiative to identify and define risks, and the weak awareness of risks is the main reason for the occurrence of financial risks in enterprises.

2) The capital structure within the enterprise is not reasonable. For example, the financial leverage is too high and most assets or owner's equity come from liabilities. This can cause the company to incur financing risks, and the leverage effect makes the company take greater financial risks in case of losses, resulting in the 
inability to repay liabilities, or even the need to sell corporate assets to repay debts.

3) Irrational financial decisions. The company's internal decisions do not consider the changes in the market, resulting in mistakes in its internal financial management decisions, which are divided into financing management, investment management, operational management and inventory management. If mistakes are made in these financial management processes, the company will take greater risks.

The continuous improvement of managers' understanding of risk has led to the assessment of financial risk being gradually taken seriously by enterprises. The establishment of financial risk assessment model has also attracted extensive attention from researchers. Based on the existing pieces of literature, there are two types of financial risk assessment models, subjective and objective. Subjective methods include AHP hierarchical analysis and expert evaluation, while objective methods include neural network model, logistic regression model and SVM model. The financial risk assessment models based on subjective assessment are less accurate due to the influence of personal factors in expert assessment ${ }^{[5]}$. Neural networks can learn from large amounts of data and can then classify and predict the data. However, due to its "black box" nature, the predicted results and the process of producing the results cannot be interpreted and understood. Also, the training cost of application networks is high. Meanwhile, there are undeniable advantages of using neural networks. Researcher Zhang (2018) ${ }^{[6]}$ stated that neural network models can identify nonlinear relationships between variables. Therefore, the accuracy of neural network models in predicting the financial risk of small and medium-sized companies is very high. In addition, Yan
(2021) ${ }^{[7]}$ constructed a risk warning model based on a neural network model for the communication equipment manufacturing industry with an accuracy rate of $95 \%$. Logistic regression model is also a common method to establish the early warning model of financial risk of enterprises [8]. Yang (2021) ${ }^{[9]}$ established an early warning model of financial risk using Logistic regression and found five factors that significantly indicate financial risk, these are debt to working capital ratio, times interest earned ratio, debt to asset ratio, sustainable growth rate, accounts receivable turnover. However, the drawbacks of logistic regression are also very significant. Logistic regression does not perform well when the feature space is large, and it cannot handle multiple types of features and variables at the same time ${ }^{[10-11]}$. Another method commonly used in early warning modeling of financial risk is SVM (support vector regression), and its main advantage is not dependent on a large amount of data ${ }^{[12]}$. However, SVM can only solve the problem of binary classification and is not very efficient when there are many observation samples ${ }^{[13]}$. Therefore, there are limitations to the measurement of financial risk in the existing literature.

Financial risk management is crucial for the sustainable operation of a company. Therefore, the purpose of this paper is to develop a financial risk assessment model to help companies anticipate risks from internal factors in advance and take proactive financial management measures to turn risks into benefits or reduce losses from risks.

\section{MODEL}

\subsection{Notations}

Table 1 Notations

\begin{tabular}{ll}
\hline Notations & Meaning \\
\hline$H$ & Information entropy \\
$P(X)$ & Probability of occurrence of event X \\
$F$ & Assessment Matrix \\
$E$ & Enterprises to be evaluated \\
$X_{i j}$ & The specific value of the $\mathrm{i}^{\text {th }}$ enterprise to be evaluated under the \\
& $\mathrm{j}^{\text {th }}$ indicator \\
$m$ & Number of financial indicators \\
$m$ & Number of enterprises to be assessed \\
$V_{i j}$ & Standardized indicators \\
$P\left(X_{i j}\right)$ & The weight of the $\mathrm{i}^{\text {th }}$ enterprise to be evaluated under the $\mathrm{j}$ \\
& evaluation index \\
$e_{j}$ & Entropy weight of the $\mathrm{j}^{\text {th }}$ indicator \\
$w_{j}$ & Weight of the $\mathrm{j}^{\text {th }}$ indicator \\
$R$ & Weighted Decision Matrix \\
$r_{i j}$ & Weighted indicator values \\
$S_{j}^{+}$ & Positive ideal solution \\
$S_{j}^{-}$ & Negative ideal solution \\
$d_{i}^{+}$ & Distance of the indicator from the positive ideal solution \\
$d_{i}^{-}$ & Distance of the indicator from the negative ideal solution \\
$R_{i}$ & Relative fit to the positive ideal solution \\
\hline
\end{tabular}




\subsection{Methodology}

In order to establish a comprehensive and objective internal financial risk assessment model, this paper uses Entropy Weight TOPSIS (Technique for Order Preference by Similarity to an Ideal Solution) to determine the weights of different financial indicators to establish the basis of risk evaluation. At the same time, Entropy Weight TOPSIS can make the risk evaluation more objective to a certain extent by introducing more variables, which can compensate for the shortcomings of other methods ${ }^{[14]}$. The model established in this paper can help enterprises and their related decision-makers better evaluate possible financial risks and propose countermeasures in advance to make correct management decisions.

Entropy Weight TOPSIS is a comprehensive evaluation method that integrates entropy weight method and TOPSIS to find the best solution in multi-objective analysis while ensuring the objectivity of the evaluation.

This paper first selects the financial indicators that can represent the financial risk in 15 listed companies located in Shanghai, China, calculates the indicator weights by entropy weight method, and uses the TOPSIS method to rank the risk evaluation value to build a financial risk assessment model. Choosing firms that are all located in Shanghai with similar business nature can avoid any bias in the results due to the different external environment.

The objective assignment of the entropy method can increase the accuracy of data weights. Entropy is a measure of uncertainty, and the amount of information is related to the size of entropy. The greater the entropy, the more information it contains, the more important the variable is, and therefore the greater the weight assigned to it. Information entropy is the expectation of information; the higher the probability of something happening, the lower its information entropy [15]. Equation 1 shows the calculation of information entropy.

$$
H=-\sum \mathrm{P}(\mathrm{x}) \log \mathrm{P}(\mathrm{x}) \quad \mathrm{X} \in \mathrm{U}
$$

Assume that the objects involved in the assessment are $\mathrm{m}$ companies $\left(\mathrm{E}_{1}, \mathrm{E}_{2}, \ldots, \mathrm{E}_{\mathrm{m}}\right)$, and $\mathrm{n}$ indicators are evaluated $\left(X_{1}, X_{2}, \ldots, X_{n}\right)$

$\mathrm{m} * \mathrm{n}$ data are obtained in the assessment matrix

$$
F_{x}=\left[\begin{array}{ccccc}
E_{1} & X_{1} & X_{12} & \cdots & X_{1 n} \\
E_{2} & X_{2} & X_{22} & \cdots & X_{2 n} \\
\vdots & \vdots & \vdots & \vdots & \vdots \\
E_{m} & E_{m 1} & E_{m 2} & \cdots & X_{m n}
\end{array}\right]
$$

Since the units of the selected indicators are not identical, the data need to be standardized.

For positive indicators which have the larger the better values:

$$
V_{i j}=\frac{X_{i j}-\min \left(X_{1 j}, X_{2 j}, \ldots, X_{m j}\right)}{\max \left(X_{1 j}, X_{2 j}, \ldots, X_{m j}\right)-\min \left(X_{1 j}, X_{2 j}, \ldots, X_{m j}\right)}
$$

For negative indicators which have the smaller the better values:

$$
V_{i j}=\frac{\min \left(X_{1 j}, X_{2 j}, \ldots, X_{m j}\right)-X_{i j}}{\max \left(X_{1 j}, X_{2 j}, \ldots, X_{m j}\right)-\min \left(X_{1 j}, X_{2 j}, \ldots, X_{m j}\right)}
$$

The entropy value of the indicator $\mathrm{j}$ is

$$
e_{j}=-\frac{1}{\log (n)} \sum_{i=1}^{n} P\left(X_{i j}\right) \log P\left(X_{i j}\right)
$$

Where

$$
P\left(X_{i j}\right)=\frac{V_{i j}}{\Sigma_{j=1}^{n}}(i=1,2, \ldots m ; j=1,2, \ldots, n)
$$

The weight of the $\mathrm{j}$ indicator is

$$
W_{j}=\frac{1-e_{j}}{\sum_{j=1}^{m}\left(1-e_{j}\right)}
$$

The weight of each indicator is multiplied with the standardized matrix to obtain the weighted decision matrix

$$
R=\left(r_{i j}\right)_{m \times n}
$$

Where: $\quad r_{i j}=W_{j} \times V_{i j}(\mathrm{i}=1,2, \ldots, \mathrm{n})$

Positive ideal solution $S_{j}^{+}=\left\{\begin{array}{l}\max \left(r_{i j}\right), j=1,2, \ldots, n ; X_{j} \text { is positive indicator } \\ \min \left(r_{i j}\right), j=1,2, \ldots, n ; X_{j} \text { is negative indicator }\end{array}\right.$

Negative ideal solution $S_{j}^{-}=\left\{\begin{array}{l}\min \left(r_{i j}\right), j=1,2, \ldots, n ; X_{j} \text { is positive indicator } \\ \max \left(r_{i j}\right), j=1,2, \ldots, n ; X_{j} \text { is negative indicator }\end{array}\right.$

Calculate the evaluation value of the program

Distance of the indicator from the positive ideal solution

$$
d_{i}^{+}=\sqrt{\sum_{j=1}^{n}\left(S_{j}^{+}-r_{i j}\right)^{2}}, i=1,2, \ldots, m
$$

Distance of the indicator from the negative ideal solution

$$
d_{i}^{-}=\sqrt{\sum_{j=1}^{n}\left(S_{j}^{-}-r_{i j}\right)^{2}}, i=1,2, \ldots, m
$$

Relative fit to the positive ideal solution

$$
R_{i}=\frac{S d_{i}^{-}}{S d_{i}^{-}+S d_{i}^{+}}, i=1,2, \ldots, m
$$

Rank the compliments to be evaluated according to the final evaluation value 


\subsection{Establishment of Risk Measurement Index System}

A comprehensive assessment of financial risk requires the analysis of multiple indicators. In this paper, financial indicators reflecting the solvency, profitability, activity ability and growth capacity within the enterprise are selected to establish a model for measuring the financial risk of the enterprise ${ }^{[16]}$.

Solvency is the ability of an enterprise to repay its debts as they fall due. Solvency indicators include shortterm solvency and long-term solvency, which reflect an enterprise's ability to pay currently maturing and longterm debts, respectively. If an enterprise cannot repay its debts as they fall due on time, it will affect its regular operation and trigger financial risks. The leading indicators of solvency are as follows.

1) Current Ratio, which refers to an enterprise's ability to pay its short-term liability, is calculated by dividing current assets from current liabilities.

2) Quick Ratio, which measures an enterprise's capacity to pay its short-term liabilities without selling its inventories, is calculated by dividing quick assets from current liabilities.

3) Times Interest Earned Ratio, which is used to measure an enterprise's ability to pay its interest expenses through operating profits, is equal to earnings before interest and tax divided by the interest expenses.

4) Debt-To-Asset Ratio, which is an indicator to identify an enterprise's financial leverage and how much of the enterprise's total assets are raised through liabilities, is calculated by dividing total liabilities by total assets.

5) Debt-To-Equity Ratio, which shows debt to equity ratio in an enterprise's capital sources for building up assets, is calculated as the company's long-term debt divided by shareholders' equity.

A company's activity ability is its capacity to use its assets to earn profits. The activity ability indicator shows how well a company's capital is working and how efficiently and effectively it uses its assets. Activity ability reflects the allocation of assets in an enterprise. The main indicators of operating capacity are as follows.

6) Receivable Turnover, which is a ratio that measures the average times of conversions of accounts receivable into cash in a certain period, is equal to the net credit sales divided by the average of accounts receivable. The higher the receivable turnover, the faster the company can recover its accounts, and the smaller the bad debt losses.

7) Inventory Turnover, refers to the times that the inventory is realized in a certain period. The faster the inventory turnover rate, the less capital occupied in the inventory, and the stronger the liquidity. The inventory turnover is equal to the cost of goods sold divided by the average inventory.

8) Operating Cycle, which refers to the period from when the inventory is sold until the cash is recovered, is equal to days sales outstanding plus days of inventory turnover. The shorter the operating cycle, the higher the efficiency of the company's inventory management.

9) Total Asset Turnover, which measures the efficiency of asset use over a period. The greater the total asset turnover, the stronger the company's sales ability. It is calculated by dividing total assets by total sales.

Profitability refers to a company's ability to earn profits and reflects how well it operates over time. The stronger the profitability, the lower the likelihood of financial risk for the enterprise. The main indicators of profitability are as follows.

10) Operating Profit Margin, which is calculated by dividing operating profit by revenue. The higher the operating profit margin, the stronger the profitability of the company and the stronger the control of its operating expenses.

11) Net Profit Margin, which is obtained by dividing net profit by sales. It refers to the profit margin after deducting all costs, expenses, and taxes. When the percentage of tax to interest is high, the net profit margin cannot fully reflect the enterprise's profitability.

12) Return on Asset, which calculates the net profit created per unit of asset, is net profit divided by the total assets.

13) Return on Equity, which reflects the enterprise's ability to generate net profits using net assets, is an indicator of the return on investment relative to shareholder equity. It is obtained by dividing the company's net income by the shareholder's equity.

The growing capability of a company is the trend and rate of future growth of a business, which includes the increase in profits, assets, and owner's equity. Business growth capacity indicators measure the ability of a business to expand its operations in the future. The main indicators of growth capacity are as follows.

14) Net Profit Growth Rate, is the ratio of the increase in net profit to the net profit of the previous period. The higher the net profit growth rate, the better the company's growth ability and development status.

15) Net Asset Growth Rate, refers to the ratio of the increase in net assets to the total net assets of the previous period. It is an important indicator to measure changes in the total size of the enterprise.

16) Main Business Income Growth Rate, is the ratio of the main business income change to the previous period's main business income. The main business 
income growth rate can be used to measure the company's product life cycle and determine the stage of the company's development. If the growth rate exceeds $10 \%$, it indicates that the company is in the growth stage.

In addition to the debt-to-asset ratio $\left(\mathrm{X}_{4}\right)$, debt-toequity ratio $\left(\mathrm{X}_{5}\right)$ and Operating Cycle $\left(\mathrm{X}_{8}\right)$ are positive indexes, because the smaller the value of these three indicators, the better the company is operating and the less financial risk it faces ${ }^{[1]}$. Yet, the other indicators are all better indicators the larger they are.

Table 2 Risk Measurement Index System

\begin{tabular}{lll}
\hline $\begin{array}{l}\text { Type of the } \\
\text { index }\end{array}$ & Index & Notation \\
\hline Solvency & Current Ratio & $\mathrm{X}_{1}$ \\
& Quick Ratio & $\mathrm{X}_{2}$ \\
& Times Interest Earned & $\mathrm{X}_{3}$ \\
& Ratio & \\
& Debt-To-Asset Ratio & $\mathrm{X}_{4}$ \\
& Debt-To-Equity Ratio & $\mathrm{X}_{5}$ \\
Activity & Receivable Turnover & $\mathrm{X}_{6}$ \\
& Inventory Turnover & $\mathrm{X}_{7}$ \\
& Operating Cycle & $\mathrm{X}_{8}$ \\
& Total Asset Turnover & $\mathrm{X}_{9}$ \\
Profitability & Operating Profit & $\mathrm{X}_{10}$ \\
& Margin & \\
& Net Profit Margin & $\mathrm{X}_{11}$ \\
& Return on Asset & $\mathrm{X}_{12}$ \\
& Return on Equity & $\mathrm{X}_{13}$ \\
& Net Profit Growth Rate & $\mathrm{X}_{14}$ \\
Growth & Net Asset Growth Rate & $\mathrm{X}_{15}$ \\
& Main Business Income & $\mathrm{X}_{16}$ \\
& Growth Rate & \\
\hline
\end{tabular}

\subsection{Results}

After determining the positivity and negativity of the data and performing the standardization process, the entropy weight method was used to find out the weight of each indicator, and the larger the weight indicates the greater the influence of the indicator on the financial risk of the enterprise. The financial data used are from the financial statement report of the chosen companies. The results are shown in Table 3 . The weights are multiplied with the data to obtain a new matrix, and the relative proximity is found. The smaller the rating value $R_{i}$, the greater the financial risk faced by the enterprise. The results are shown in Table 4.

Table 3 Results of Entropy Weighting

\begin{tabular}{lll}
\hline Indicator & $\begin{array}{l}\text { Information } \\
\text { entropy }\end{array}$ & Weight \\
\hline $\mathrm{X}_{1}$ & 0.9304 & $2.92 \%$ \\
$\mathrm{X}_{2}$ & 0.9012 & $4.15 \%$ \\
$\mathrm{X}_{3}$ & 0.9756 & $1.02 \%$ \\
$\mathrm{X}_{4}$ & 0.8981 & $4.28 \%$ \\
$\mathrm{X}_{5}$ & 0.9621 & $1.59 \%$ \\
$\mathrm{X}_{6}$ & 0.6556 & $14.46 \%$ \\
$\mathrm{X}_{7}$ & 0.5319 & $19.65 \%$ \\
$\mathrm{X}_{8}$ & 0.9669 & $1.39 \%$ \\
$\mathrm{X}_{9}$ & 0.8309 & $7.10 \%$ \\
$\mathrm{X}_{10}$ & 0.7190 & $11.80 \%$ \\
$\mathrm{X}_{11}$ & 0.7226 & $11.65 \%$ \\
$\mathrm{X}_{12}$ & 0.8177 & $7.65 \%$ \\
$\mathrm{X}_{13}$ & 0.8456 & $6.48 \%$ \\
$\mathrm{X}_{14}$ & 0.9712 & $1.21 \%$ \\
$\mathrm{X}_{15}$ & 0.9519 & $2.02 \%$ \\
$\mathrm{X}_{16}$ & 0.9376 & $2.62 \%$ \\
\hline
\end{tabular}

The weight of evaluation indicators shows that, among the financial management indices, inventory turnover $\left(\mathrm{X}_{7}\right)$ is the most significant indicator that influences a company's financial risk and is followed by receivable turnover $\left(\mathrm{X}_{6}\right)$, operating profit margin $\left(\mathrm{X}_{10}\right)$, and net profit margin $\left(\mathrm{X}_{11}\right)$. It implies that the indices that show the activity ability and profitability need to be paid more attention by the company in terms of managing financial risk.

Table 4 Results of TOPSIS

\begin{tabular}{ccccc}
\hline Enterprise & $\boldsymbol{d}_{\boldsymbol{i}}^{+}$ & $\mathbf{d}_{\mathbf{i}}^{-}$ & $\boldsymbol{R}_{\boldsymbol{i}}$ & Rank \\
\hline sh600009 & 0.24 & 0.212 & 0.47 & 1 \\
sh600061 & 0.264 & 0.172 & 0.395 & 2 \\
sh600612 & 0.266 & 0.169 & 0.389 & 3 \\
sh600019 & 0.286 & 0.112 & 0.282 & 4 \\
sh600688 & 0.278 & 0.105 & 0.273 & 5 \\
sh600021 & 0.293 & 0.074 & 0.202 & 6 \\
sh603868 & 0.303 & 0.063 & 0.173 & 7 \\
sh600026 & 0.296 & 0.059 & 0.167 & 8 \\
sh600104 & 0.299 & 0.059 & 0.165 & 9 \\
sh600018 & 0.303 & 0.055 & 0.153 & 10 \\
sh600115 & 0.298 & 0.044 & 0.128 & 11 \\
sh600072 & 0.314 & 0.045 & 0.126 & 12 \\
sh600170 & 0.313 & 0.041 & 0.117 & 13 \\
sh600606 & 0.316 & 0.038 & 0.108 & 14 \\
sh600320 & 0.313 & 0.032 & 0.092 & 15 \\
\hline
\end{tabular}


The higher the relative fit to the positive ideal solution the lower the financial risk that the company is facing.

Therefore, the corporate financial risk of Shanghai Airport and SDIC Capital Co., Ltd. represented by sh600009 and sh600061 is low. However, the corporate financial risk of Greenland Holdings Co., Ltd. and Zhenhua Port Machinery Company represented by sh600606 and sh600320 is relatively high.

\section{CONCLUSIONS}

Using the entropy weight TOPSIS method not only can accurately assess the financial risks of enterprises, but also to identify indicators affecting corporate financial risks by empowering the indicators. Entropy Weight TOPSIS method can objectively reflect the enterprise financial risk situation. Through the analysis of this paper, the indicators that have a significant impact on the financial risk of enterprises in Shanghai are inventory turnover $\left(\mathrm{X}_{7}\right)$, receivable turnover $\left(\mathrm{X}_{6}\right)$, operating profit margin $\left(\mathrm{X}_{10}\right)$, and net profit margin $\left(\mathrm{X}_{11}\right)$. Therefore, in the company's daily operation, managers should always pay attention to these indicators to detect and intervene in the generation of financial risks.

The underlying reason behind the results is that inventory turnover and receivable turnover affect the cash conversion cycle, an indicator for liquidity that measures the efficiency of a company managing its working capital. Low turnover means an extended cash conversion cycle, leading to low liquidity, which is a potential risk for the company. Moreover, profit margins are for a company to review its business risk. If the company is not able to generate income, there will be financial risk, especially in terms of liquidity risk caused by the shortage of cash flows.

In summary, the established financial risk measurement model using entropy weight TOPSIS can be more objectively identified by the main financial indicators that lead to the company's high risk. This paper can enlighten companies to actively engage in the financial risk assessment process, timely discover and assess factors that lead to risks, and adopt corresponding strategies to deal with the risks.

\section{REFERENCES}

[1] Wang, N. (2017). Research on Financial Risk Measurement of China's New Energy Listed Companies [D]. Xi'an Shiyou University.

[2] Jia, G. (2018). On the Importance of Risk Awareness in Enterprise Risk Management [J]. Modern Marketing Weekly.

[3] Pan, L. (2021). The Importance of Risk Awareness in Enterprise Financial Management. Modern Enterprise. 7, 14-15.
[4] Wu, J. (2018). Analysis of Enterprise Internal Control Management and Risk Prevention and Control Measures[J]. Finance and Accounting Study, 32, 233-235

[5] Fan, J., Liu, H. \& Hu, Y. (2020). Research on Enterprise Financial Risk Evaluation and Early Warning Based on Entropy Weight TOPSIS and Kmeans Clustering[J]. Journal of Shanghai University of Business Studies, 21(5):15.

[6] Zhang, Q. (2018). Research on Financial Early Warning of Listed Companies Based on Optimized BP Neural Network[J]. Economic Research Guide, 28, 97-98,108.

[7] Yan, H. (2021). Research on Financial Risk Early Warning of Communication Equipment Manufacturing Industry Based on Neural Network Model-Take D Company as an Example [D]. Jiangxi University of Finance and Economics.

[8] Qian, X. (2020). Literature Review of Financial Risk Early Warning[J]. Land bridge Vision, 10, 71-72, 75.

[9] Yang, B., Zhang, Y. \& Guo, W. (2021). Research on Financial Distress Diagnosis of Enterprises Based on Logistic Regression Model[J]. Journal of Systems Science. 3, 84-87.

[10] Yan, C. \& Wang, Z. (2018). Research on Early Warning Model of Financial Risks of Life Insurance Companies Based on Pls-Logit Model[J]. Technology and Innovation Management, 39(1): 102-110.

[11] Tao, Z. (2013). Research on Financial Risk Early Warning of Listed Companies Based on Logistic Model[J]. Business Economics, 17, 109-112.

[12] Xu, X. (2021). Construction of financial early warning model for listed companies based on SVM and ANN[J]. Automation Technology and Application, 40(5):4.

[13] Liu, P. \& Zeng, Z. (2021). Financial Credit Risk Evaluation of Pharmaceutical Supply Chain Based on GBDT[J]. Friends of Accounting. 16, 24-31.

[14] Li, X. (2021). TOPSIS Model with Entropy Weight for Eco Geological Environmental Carrying Capacity Assessment[J]. Microprocessors and Microsystems, 2021:103805.

[15] Chai, R. \& Luo J. (2021). Research on Financial Risk Evaluation of Thermal Power Enterprises Based on Entropy TOPSIS Method[J]. Modern Business, (7):4.

[16] Zutter, C. J. \& Gitman, L. J. (1988). Principles of managerial finance, 5th ed., Harper \& Row, New York. 